\title{
Non-inferiority comparative clinical trial between early oral REFEEDING and usual oral REFEEDING in predicted mild acute biliary pancreatitis
}

Edgard Efrén Lozada-Hernández ${ }^{1 *}$ (D), Omar Barrón-González², Santa Vázquez-Romero², Martin Cano-Rosas² and Evelia Apolinar-Jimenez ${ }^{3}$

\begin{abstract}
Background: The aim of the study was to compare the onset of oral feeding in the first $24 \mathrm{~h}$ after hospital admission with usual oral refeeding and determine whether the timing of the onset of oral feeding influences the recurrence of pain or alters the blood levels of pancreatic enzymes in patients with predicted mild acute biliary pancreatitis.
\end{abstract}

Methods: This non-inferiority randomized controlled trial was carried out between September 2018 and June 2019 after receiving authorization from the ethics committee for health research. Patients with a diagnosis of predicted mild acute biliary pancreatitis were divided into Group A (early oral refeeding, EOR) and Group B (usual oral refeeding, UOR). Outcome measures included pancreatic lipase levels, the systemic inflammatory response (concentrations of leukocytes), feasibility (evaluated by abdominal pain recurrence), the presence and recurrence of gastrointestinal symptoms and the length of hospital stay.

Results: Two patients in the EOR group experienced pain relapse (3.2\%), and four patients in the UOR group experienced pain relapse $(6.77 \%)$ after oral refeeding $(p=0.379)$. The presence of nausea or vomiting after the onset of oral refeeding was not different between the two groups $(p=0.293)$. The onset of oral refeeding was approximately $48 \mathrm{~h}$ later in the UOR group. The length of hospital stay was 5 days in the EOR group and 8 days in the UOR group ( $p=0.042$ ), and this difference was also manifested in higher hospital costs in the UOR group $(p=0.0235)$.

Conclusion: Compared with usual oral refeeding, early oral refeeding is safe in predicted mild acute biliary pancreatitis patients, does not cause adverse gastrointestinal events, and reduces the length of hospital stay and costs.

Trial registration: Early oral refeeding in mild acute pancreatitis (EORVsUOR). NCT04168801, retrospectively registered (November 19, 2019).

Keywords: Mild acute biliary pancreatitis, Oral feeding, Non-inferiority clinical trial, Nil per os

\footnotetext{
* Correspondence: edgardlozada@hotmail.com

'Department of Surgery and Clinical Research, Hospital Regional de Alta

Especialidad del Bajío, Circuito Quinta los Naranjos \# 145 B. Colonia Quinta

los Naranjos, León, Guanajuato, Mexico

Full list of author information is available at the end of the article
}

C C The Author(s). 2020 Open Access This article is licensed under a Creative Commons Attribution 4.0 International License, which permits use, sharing, adaptation, distribution and reproduction in any medium or format, as long as you give appropriate credit to the original author(s) and the source, provide a link to the Creative Commons licence, and indicate if changes were made. The images or other third party material in this article are included in the article's Creative Commons licence, unless indicated otherwise in a credit line to the material. If material is not included in the article's Creative Commons licence and your intended use is not permitted by statutory regulation or exceeds the permitted use, you will need to obtain permission directly from the copyright holder. To view a copy of this licence, visit http://creativecommons.org/licenses/by/4.0/ The Creative Commons Public Domain Dedication waiver (http://creativecommons.org/publicdomain/zero/1.0/) applies to the data made available in this article, unless otherwise stated in a credit line to the data. 


\section{Background}

Acute pancreatitis (AP) is the result of an inflammatory process in the pancreas, and although the causes are varied, the pathophysiology and management are similar. AP is most commonly caused by bile stones, presents with different degrees of severity, and causes local and systemic complications, leading to high catabolic, hypermetabolic, and hyperdynamic stress states [1]. The currently widely used severity assessment tool used is the revised Atlanta classification, wherein AP is classified as mild, moderate and severe [2]. As no curative therapy is currently available for AP, early treatment consists of supportive care, which includes adequate fluid resuscitation, pain management and enteral nutrition [3]. Nutrition therapy is an essential component of AP management [4]. The published IAP/APA guidelines recommended that oral feeding in patients with predicted mild pancreatitis can be restarted once abdominal pain has decreased and the levels of inflammatory markers have improved (Recommendation G. Nutritional support 20-Grade 2B, strong agreement) [5]. This recommendation is reinforced by other authors with similar clinical results $[6,7]$. Pancreatic rest by the nil per os (NPO) strategy has been considered necessary in patients with AP until the resolution of abdominal pain and decreases in the levels of pancreatic and inflammatory markers [8]. This trend has changed; now, it is clear that early oral refeeding (OR) for mild PA not only provides adequate caloric intake but also may improve clinical outcomes. It has been hypothesized that the combination of disturbed intestinal motility, microbial overgrowth and increased permeability of the gut can lead to bacterial translocation, thus causing infection and pancreatic necrosis $[9,10]$.

OR may reduce translocation by stimulating intestinal motility and reducing bacterial overgrowth, thereby maintaining mucosal gut integrity [11, 12]. Additionally, infection complications, organ failure and mortality are decreased in patients receiving early oral refeeding compared with those receiving routine total parenteral nutrition $[13,14]$. In patients with predicted mild AP, numerous studies have shown that a normal oral diet can be resumed once the pain has started to decrease [1, 15-17]. However, it remains unclear what the optimal timing is for OR. There is still no consensus about the definition of "early" refeeding, the criteria for refeeding, the estimated daily energy intake and type intake [18].

The aim of the present study was to compare the early onset of OR (within the first $24 \mathrm{~h}$ after hospital admission) with usual OR (25-72 h after hospital admission) and determine whether the early introduction of OR influences the recurrence of pain or alters the blood levels of pancreatic enzymes in patients with mild acute pancreatitis.

\section{Methods}

\section{Patients}

This randomized controlled trial was carried out between September 2018 and June 2019 after authorization from the ethics committee for health research. All patients admitted to the Surgery Department with a diagnosis of biliary acute pancreatitis (BAP), with a predicted mild episode severity based on the criteria and a symptom onset time less than $24 \mathrm{~h}$, were screened for inclusion in the study. Patients with pancreatitis stemming from another cause, (i.e., pregnancy, history of chronic pancreatitis), those under 18 or over 75 years, and those with predicted moderately severe or severe acute biliary pancreatitis were excluded. Written informed consent was signed from all patients.

\section{Sample size}

A total of 124 patients were randomized in this study. The sample size was calculated according to the formula published by Bouman et al. 2015 [19], in which a percentage of success of $90 \%$ was estimated with the standard treatment compared to $85 \%$ for the experimental management, with a margin of no less than $5 \%$, an alpha of $0.05 \%$, a beta of $20 \%$, and a percentage of estimated losses of approximately $10 \%$, for a total of 62 patients per group.

\section{Definitions}

The diagnosis of AP was established when the patient presented two or more of the three following findings: typical abdominal pain, elevation of serum pancreatic enzymes (amylase and/or lipase) more than three times the upper limit of normal, and imaging study (ultrasonography or computed tomography) results suggestive of AP [20]. On admission, the etiology of acute pancreatitis was determined using detailed personal (i.e., previous acute pancreatitis, known gallstone disease, alcohol intake, medication and drug intake, known hyperlipidemia, trauma, recent invasive procedures such as endoscopic retrograde cholangiopancreatography (ERCP)) and family histories of pancreatic disease, physical examinations, laboratory serum tests (liver enzymes, calcium, triglycerides), and imaging (right upper quadrant ultrasonography). Patients with acute pancreatitis from a cause other than biliary pancreatitis were excluded [5].

\section{Severity assessment}

The severity assessment of AP was performed based on the revised Atlanta classification, and the severity was classified as mild, moderately severe and severe. In the absence of organ failure and local or systemic complications, AP was labeled as predicted mild; it was defined using the modified Marshall scoring system [21], and only the patients with complete information for the determination of the severity of AP were included in this study. 


\section{Protocol}

Once the diagnosis of acute biliary pancreatitis was confirmed and the course was predicted to be mild, written informed consent was obtained.

Patients were divided into Group A (early oral refeeding, EOR) and Group B (usual oral refeeding, UOR) through a random number table generated with the commercial statistics program IBM SPSS version 25 (the numbers generated by the program were for the experimental group).

Due to the characteristics of the study, only simple blinding was possible (the doctor who performed the statistical analysis).

Both groups were medically managed according to the IAP and APA guidelines [5].

Fluid therapy with crystalloid solution (Hartmann) was administered at an initial bolus of $10 \mathrm{~mL} / \mathrm{kg}$, followed by the infusion of $1.5 \mathrm{~mL} / \mathrm{kg} / \mathrm{h}$ for $24 \mathrm{~h}$.

Pain was managed with the weak opioid tramadol 50 mg every $6 \mathrm{~h}$ and paracetamol $1 \mathrm{~g}$ every $8 \mathrm{~h}$ with continuous evaluation with the numerical analogue scale (NAS) to determine the need for extra doses.

\section{Oral Refeeding}

Group A: In the EOR group, once a patient had a score of 1-3 on the NAS, he was asked about symptoms such as nausea or vomiting; if he did not have such symptoms, then he received OR as indicated between 16 and $24 \mathrm{~h}$ after admission.

Group B: In the UOR group, once a patient had a score of $1-3$ on the NAS, he was asked about symptoms such as nausea or vomiting; if he did not have such symptoms, then he received OR as indicated between 25 and $72 \mathrm{~h}$ after admission.

\section{Type of diet}

In both groups, the initial diet was the same to avoid influencing the outcomes.

The soft diet consisted of one $900 \mathrm{Kcal}$ meal per day, composed of $86.7 \%$ carbohydrates (190 g), 13.3\% protein (30 g) and $0 \%$ lipids ( $0 \mathrm{~g})$.

When the diet was adequately tolerated and there was no evidence of clinical complications or deterioration, a normal diet was indicated, and the follow-up continued.

\section{Endpoints}

During the entire hospital stay or until surgery, the Marshall scale continued to indicate the classification of AP as mild. None of the patients evaluated had an aggravation of the episode. Follow-up was conducted 2 months postsurgery.

The outcome measures were the levels of the pancreasspecific markers amylase and lipase, the systemic inflammatory response (concentrations of leukocytes), feasibility (evaluated by abdominal pain recurrence), the presence and recurrence of gastrointestinal symptoms and the length of hospital stay.

\section{Data collection}

Laboratory data, such as the levels of leukocytes, amylase and lipase, were collected after inclusion in the study and after 24 and $48 \mathrm{~h}$ of oral refeeding. Clinical data included age, sex, time from onset of pain (baseline), Marshall scores at admission and after starting oral feeding, gastrointestinal symptoms, abdominal pain, days until solid food intake, pain relapses, complications, length of hospital stay and readmission.

\section{Statistical analysis}

Data are presented as frequencies and percentages, and comparisons between groups were performed using the $x^{2}$ test for binary data or Fisher's exact test. Continuous variables are presented as the median and range or interquartile range and were compared using the MannWhitney U-test or Student's t test if they met the criteria for a normal distribution. $P$-values less than 0.05 were considered significant. Statistical analyses were performed with SPSS version 25.0.0. Analysis by intention to treat was used.

\section{Results}

A total of 124 patients were randomized, and 120 were included (61 in the EOR group and 59 in the UOR group). As shown in Fig. 1 (CONSORT diagram); one patient from the EOR group was excluded because of persistent pain and his consequent inability to receive oral refeeding. Three patients in the UOR group were excluded because one patient had no improvement in pain; computed tomography was performed, and peripancreatic collections were identified. Two patients were operated on without starting OR. Fig. 1. These four patients who were excluded from the study represent a loss of $3.2 \%$ of the study population.

The demographic data and clinical parameters of patients at admission are presented in Table 1. There were no statistically significant differences between the two groups.

The comparisons of outcome variables between the two groups are presented in Table 2. Two patients in the EOR group experienced pain relapse (3.2\%), and four patients in the UOR group experienced pain relapse $(6.77 \%)$ after OR $(p=0.379)$. Another characteristic that determines tolerance of OR is the presence of gastrointestinal symptoms; there was no difference in the occurrence of nausea or vomiting after the onset of OR between the two groups $(p=0.293)$.

The serum lipase level could indicate recurrence; in the EOR group, the serum lipase level did not increase 


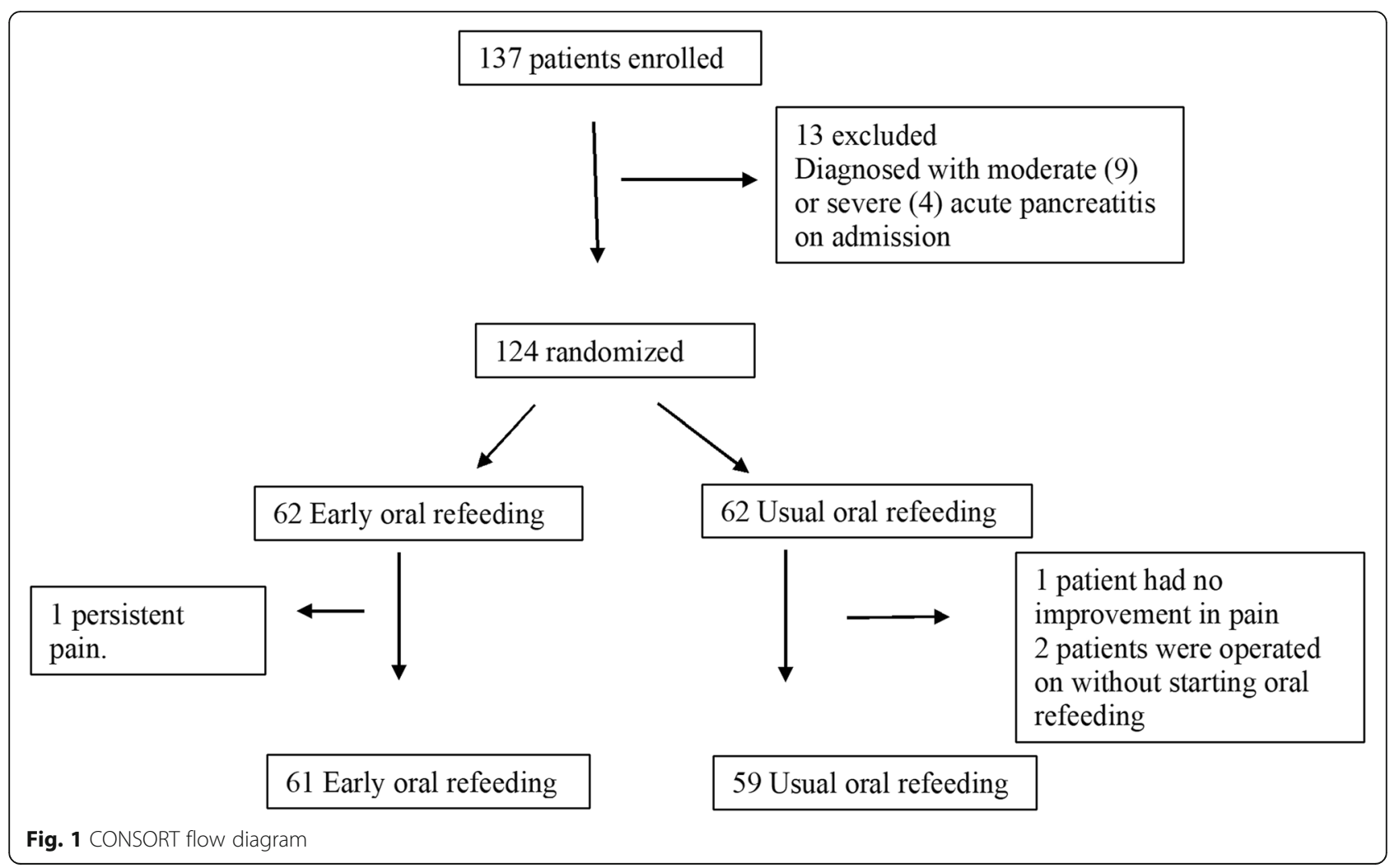

after the onset of OR compared to the level at admission. In the UOR group, a decrease in the serum lipase level was observed after the start of OR compared with the baseline level at admission; however, this finding was expected and was in fact an inclusion criterion for this group.

The systemic inflammatory response was evaluated based on the leukocyte levels, and the behavior was very similar to that described for the lipase levels. The levels in the EOR group did not increase after the onset of the OR compared to the level at admission.

The length of hospital stay and follow-up are presented in Table 3. The onset time of OR was approximately $48 \mathrm{~h}$ longer in the UOR group. The length of stay

Table 1 Demographic data and clinical parameters on admission

\begin{tabular}{llll}
\hline Variable & EOR $n=61$ & UOR $n=59$ & $\mathrm{p}$ \\
\hline Age (years) & $45.3(17.02)$ & $50.01(14.2)$ & $0.106^{\mathrm{a}}$ \\
Sex (female/male) & $46 / 15$ & $41 / 18$ & $0.271^{\mathrm{b}}$ \\
Weight (kg) & $73.2(11.08)$ & $71.9(9.58)$ & $0.499^{\mathrm{a}}$ \\
Height (meters) & $1.61(0.06)$ & $1.58(0.03)$ & $0.969^{\mathrm{a}}$ \\
BMl (kg/m $\left.{ }^{2}\right)$ & $28.04(3.87)$ & $27.6(4.67)$ & $0.531^{\mathrm{a}}$
\end{tabular}

${ }^{a}$ Continuous variables are presented as the mean and standard deviation and were compared using Student's t test

${ }^{\mathrm{b}}$ Data are presented as frequencies, and comparisons between groups were performed using the $x^{2}$ test in the hospital was 5 days in the EOR group and 8 days in the UOR group $(p=0.042)$, and this difference was also manifested in higher hospital costs in the UOR group $(p=0.0235)$.

\section{Discussion}

For decades, pancreatic rest by the nil per os (NPO) strategy was considered necessary for patients with AP until the abdominal pain resolved and the levels of pancreatic and inflammatory markers normalized. This trend has changed now; early enteral feeding is accepted in the treatment of AP, but there is still no consensus about the definition of early oral refeeding.

The concept of early oral refeeding includes the time between admission and the start of the diet and the presence of adverse events, including abdominal pain relapse and gastrointestinal symptoms (nausea and vomiting).

In this study, we found that EOR is safe within the first $24 \mathrm{~h}$ after hospital admission and that there is no difference in the presence of abdominal pain relapse, nausea or vomiting compared with standard oral refeeding in patients with predicted mild acute biliary pancreatitis. This study provide solid evidence for the oral intake should be started within $24 \mathrm{~h}$.

The criteria for EOR are unclear. Eckerwall GE 2007 [15] reported that his patients were "immediately allowed to drink", and the diet start time was 1 day. 
Table 2 Comparison of outcome variables between the two groups

\begin{tabular}{|c|c|c|c|}
\hline Variable & $\mathrm{EOR} n=61$ & UOR $n=59$ & $\mathrm{p}$ \\
\hline Lipase (0 h) IU/L & $547.1(245-760)$ & $530(240-840)$ & $0.644^{\mathrm{a}}$ \\
\hline Lipase IU/L after oral refeding & $485(174-530)$ & $110(85-200)$ & $0.665^{\mathrm{a}}$ \\
\hline Leukocytes (0 h) $10^{3} \mathrm{UL}$ & $10.2(7.29-13.7)$ & $10.3(7.8-14)$ & $0.622^{\mathrm{a}}$ \\
\hline Leukocytes after oral refeeding $10^{3} \mathrm{UL}$ & $10.8(7-13.2)$ & $7.2(7-13.2)$ & $0.658^{\mathrm{a}}$ \\
\hline Paín (NAS) (0 h) & $9(6-10)$ & $8(7-10)$ & $0.812^{\mathrm{a}}$ \\
\hline Pain (NAS) After oral refeeding & $3(0-3)$ & $3(1-4)$ & $0.842^{\mathrm{a}}$ \\
\hline Time of evolution(h) & $20(12-24)$ & $23(14-23)$ & $0.668^{\mathrm{a}}$ \\
\hline Nausea or vomiting (O h) & $39(63.9 \%)$ & $45(76.2 \%)$ & $0.186^{\mathrm{b}}$ \\
\hline Nausea or vomiting after oral refeeding & $1(1.6 \%)$ & $3(5 \%)$ & $0.293^{b}$ \\
\hline Pain relapse & $2(3.2 \%)$ & $4(6.77 \%)$ & $0.379^{b}$ \\
\hline
\end{tabular}

${ }^{a}$ Continuous variables are presented as the medians and interquartile range and were compared using the Mann-Whitney U-test

${ }^{b}$ Data are presented as frequencies and percentages, and comparisons between groups were performed using the $x^{2}$ test

Teich N 2010 [17] did not report a criterion; the onset time was determined by the randomization, and the start time for his patients was 2 days. Li J 2013 [1] reported the "feeling of hunger" as the criterion for the start of OR, and the start time for his patients was 5 days. Larino-Noia 2014 [22] reported "normal bowel sounds" as the criterion for starting OR, and the diet start time for his patients was 2 days. Our criteria were the objective measurement of symptoms, a pain score of 3-10 on the NAS, and the absence of symptoms such as nausea or vomiting. These criteria allowed OR to begin within the first $24 \mathrm{~h}$, with a $95 \%$ success rate.

Once the start time for OR is defined, the next point to clarify is the type of diet. The meta-analysis conducted by Meng et al. in 2011 [23] showed that in comparison with a clear liquid diet, early OR with a solid diet might provide better outcomes and is safe for patients with AP. Based on these results, we started with a solid diet in both groups, so the diet type did not influence the results of the study; the results show that this type of diet can be started without complications.

In a systemic review and meta-analysis, Horibe $M$ et al. 2016 [24] reported that early OR reduces the length of hospital stay without significant differences in adverse events. In our study, the hospital stay was shorter in the EOR group than in the UOR group (5 vs 8 days) $(p=0.042)$, which also led to lower hospital costs in the EOR group (2089 vs 3310 dollars) $(p=0.0235)$. This cost represents the total hospital stay expenses.
The results of this study might impact the treatment strategy and potentially reduce the cost of hospitalization for these patients.

Eckerwall GE 2007 [15] analyzed recurrence and the systemic inflammatory response, measured the pancreatic-specific serum amylase levels and CRP concentrations, and observed any significant differences between groups in any of those biochemical markers for any days evaluated. In our study, we measured serum lipase levels and leukocytes levels as parameters of recurrence and the systemic inflammatory response; we found that the timing of the onset of OR did not influence these parameters, indicating that it did not affect the natural history of the disease.

Horibe M 2020 [25] analyzed the benefits and safety of the immediate oral intake of low-fat solid food in patients with mild AP who were allowed to use opioid analgesics. They found that the beginning of the diet is safe and reduces the cost and the days of hospitalization. Our findings were similar, however we did not use fats, used it in the same way in the control group and we did not use opioids as the main analgesic, so the only difference point between both groups was the beginning of the diet.

The strengths of this study were that all patients had the same cause of AP (biliary), the disease had evolved for at least $24 \mathrm{~h}$ in all patients, and all patients received the same type of diet, increasing the homogeneity of the groups. Another strength is the clear and objective

Table 3 Hospital length of stay comparison and follow up

\begin{tabular}{llll}
\hline Variable & EOR $n=61$ & UOR $n=59$ & $\mathrm{p}$ \\
\hline Time for start OR & $18(12-22)$ & $72(32-96)$ & $0.001^{\mathrm{a}}$ \\
Hospital stay length (days) & $5(3-8)$ & $8(7-10)$ & $0.032^{\mathrm{a}}$ \\
Hospital cost (dollars) & $2089(2006-3812)$ & $3310(2810-4019)$ & $0.0235^{\mathrm{a}}$ \\
\hline
\end{tabular}

${ }^{\mathrm{a} C o n t i n u o u s ~ v a r i a b l e s ~ a r e ~ p r e s e n t e d ~ a s ~ t h e ~ m e d i a n s ~ a n d ~ i n t e r q u a r t i l e ~ r a n g e s ~ a n d ~ w e r e ~ c o m p a r e d ~ u s i n g ~ t h e ~ M a n n-W h i t n e y ~ U-t e s t ~}$ 
criteria for starting the diet. A follow-up visit was conducted 2 months postsurgery to determine the recurrence of disease.

A limitation of the present study is that the design did not include blinding. The nature of the intervention (EOR vs UOR) makes the group allocation obvious, and the patients and medical staff were aware of the classifications. Another limitation was the use of leukocytes and not CRP as a marker of the systemic inflammatory response.

\section{Conclusion}

Early OR is safe in patients with predicted mild acute biliary pancreatitis without adverse gastrointestinal events; in addition, it reduces the length of hospital stay and cost compared with usual OR.

\section{Abbreviations}

AP: Acute pancreatitis; OR: Oral refeeding; EOR: Early oral refeeding;

UOR: Usual oral refeeding; NAS: Numerical Analogue Scale; NPO: Nil per os

\section{Acknowledgments}

Not applicable.

\section{Authors' contributions}

$E E L H$, the lead author, designed the study. OBG conducted all the interviews and, alongside EELH, undertook the thematic analysis; EAJ, SVR, MCR took part in the schematic analysis. All authors have provided input into drafts of this article. All authors had full access to all the data in the study and had final responsibility for the decision to submit for publication. All authors have read and approved the manuscript in its final state.

\author{
Authors' information \\ Edgard Efren Lozada Hernandez. \\ General Surgeon. \\ Specialist in statistical methods. \\ Master of Clinical Research. \\ Research Director HRAE, UNAM, Mexico. \\ Associate prosecutor of the course of general surgery HRAEB, UNAM.
}

\section{Funding}

Not applicable.

\section{Availability of data and materials}

The datasets during and/or analysed during the current study available from the corresponding author on reasonable request.

\section{Ethics approval and consent to participate}

At recruitment, written informed consent was obtained from each subject. Our study complies with the Code of Ethics of the World Medical Association (Declaration of Helsinki) and the study was approved by the local committee for clinical research and the ethics committee.

\section{Consent for publication}

According to the study publication.

\section{Competing interests}

The authors declare that they have no competing interests.

\section{Author details}

'Department of Surgery and Clinical Research, Hospital Regional de Alta Especialidad del Bajío, Circuito Quinta los Naranjos \# 145 B. Colonia Quinta los Naranjos, León, Guanajuato, Mexico. ${ }^{2}$ Department of Surgery, Unidad Médica de Alta Especialidad Bajío, Instituto Mexicano del Seguro Social, León, Guanajuato, Mexico. ${ }^{3}$ Department of Clinical Nutrition, Hospital Regional de Alta Especialidad del Bajío, León, Guanajuato, Mexico.
Received: 17 October 2019 Accepted: 2 July 2020

Published online: 16 July 2020

\section{References}

1. Li J, Yu T, Chen G, Yuan Y, Zhong W, Zhao L, et al. Enteral nutrition within 48 hours of admission improves clinical outcomes of acute pancreatitis by reducing complications: a meta-analysis. PLoS One. 2013;8:64926. https:// doi.org/10.1371/journal.pone.0064926

2. Samanta J, Rana A, Dhaka N, Agarwala R, Gupta P, Sinha SK, Gupta YTD, Kochhar R. Ascitis in acute pancreatitis: not a silent bystander. Pancreatology. 2019:19:646-52. https://doi.org/10.1016/.jpan.2019.06.004

3. Van Dijk SM, Hallensleben NDL, Van Santvoort HC, Fockens P, Van Goor H, Bruno MJ, et al. Gut. 2017;66:2024-32. https://doi.org/10.1136/gutjnl-2016313595

4. Li X, Ma F, Jia K. Early enteral nutrition within 24 hours or between 24 and 72 hours for acute pancreatitis: evidence based on 12 RCTs. Med Sci Monit. 2014;20:2327-35.

5. Working group IAP/APA acute pancreatitis guidelines. IAP/APA evidencebased guidelines for the management of acute pancreatitis. Pancreatology. 2013:13:e1-15.

6. Istvan H, Laszlo C, Zsolt D, Gyula F, Dexso K, et al. Akut pancreatitis. Orv Hetil. 2015 Feb 15;156(7):244-61. https://doi.org/10.1556/OH.2015.30059.

7. Marta K, Farkas N, Szabo I, Illes A, Vincse A, et al. Meta-analysis of early nutrition: the benefits of enteral feeding compared to a nil per os diet not only in severe, but also in mild and moderate acute pancreatitis. Int J Mol Sci. 2016;17:1691. https://doi.org/10.3390/ijms17101691.

8. Chebli J, Gaburri P, Chebli L. Oral refeeding in mild acute pancreatitis: an old challenge. World J Gastrointest Pathophysiol. 2011;2:100-2. https://doi. org/10.4291/wjgp.v2.6.100.

9. Ammori BJ, Leeder PC, Kling RF, et al. Early increase in intestinal permeability in patients with severe acute pancreatitis: correlation with endotoxemia, organ failure and mortality. J Gastrointest Surg. 1999;3:252-62.

10. Fritz $\mathrm{S}$, Hackert T, Hartwing W, et al. Bacterial translocation and infected pancreatic necrosis in acute necrotizing pancreatitis derives from small bowel rather than from colon. Am J Surg. 2010;200:111-7.

11. Marik PE. What is the best way to feed patients with pancreatitis? Curr Opin Crit Care. 2009:15:131-8.

12. McClave SA, Heyland DK. The physiologic response and associated clinical benefits from provision of early enteral nutrition. Nutr Clin Pract. 2009;24: $305-15$

13. Yi F, Ge L, Zhao J, et al. Meta-analysis: total parenteral nutrition versus total enteral nutrition in predicted severe acute pancreatitis. Intern Med. 2012;51: 523-30.

14. Leppäniemi A, Tolonen M, Tarasconi A, Segovia-Loshe H, Gamberini E, Kirkpatrick AW, et al. 2019 WSES guidelines for the management of severe acute pancreatitis. GERCJ. 2019;14:27. https://doi.org/10.1186/s13017-0190247-0.

15. Eckerwall GE, Tingstedt BB, Bergenzaun PE, et al. Immediate oral feeding in patients with mild acute pancreatitis is safe and may accelerate recovery-a randomized clinical study. Clin Nutr. 2007;26:758-63.

16. Moraes JM, Felga GE, Chebli LA, et al. A full solid diet as the initial meal in mild acute pancreatitis is safe and result in shorther length of hospitalization: results from a prospective, randomized, controlled, doubleblind clinical trial. J Clin Gastroenterol. 2010:44:517-22.

17. Teich N, Aghdassi A, Fischer J, et al. Optimal timing of oral refeeding in mild acute pancreatitis: results of a open randomized multicenter trial. Pancreas. 2010;39:1088-92.

18. Khan S, Ranjha WA, Tariq H, Nawaz H. Efficacy of early refeeding in patients of mild acute pancreatitis. Pak J Med Sci. 2017;33(4):899-902. https://doi. org/10.12669/pjms.334.12338.

19. Bouman AC, Cate-Hoek AJ, Joore MA. Sample size estimation for Non inferiority Trials: Frequentist Approach versus Decision Theory Approach. PLoS One. 2015;10(6):e0130531.

20. Banks PA, Bollen TL, Dervenis C, Gooszen HG, Johnson CD, Sarr MG et al. Classification of acute pancreatitis 2012: revision of the Atlanta classification and definitions by international consensus. Gut. 2013;62(1): 102-11.

21. Marshall JC, Cook DJ, Christou NV, Bernard GR, Sprung CL, Sibbald WJ. Multiple organ dysfunction score: a reliable descriptor of a complex clinical outcome. Crit Care Med. 1995;23(10):1638-52. 
22. Larino-Noia J, Lindkvist B, Iglesias-Garcia J, et al. Early and/or immediately full caloric diet versus standard refeeding in mild acute pancreatitis: a randomized open-label trial. Pancreatology. 2014;14:167-73.

23. Meng WB, Li X, Li YM, et al. Three initial diets for management of mild acute pancreatitis: a meta-analysis. World J Gastroenterol. 2011;17:4235-41.

24. Horibe M, Nishizawa T, Suzuki H, Minami K, Yagahi N, et al. Timing of oral refeeding in acute pancreatitis: a systemic review and meta-analysis. United European Gastroenterol J. 2016;4(6):726-32.

25. Horibe M, Iwasaki E, Nakagawa A, Matzusaki J, Kazuhiro M, et al. Efficacy and safety of immediate oral intake in patients with mild acute pancreatitis: A Randomized controlled trial, 110724. Nutrition. 2020;74. https://doi.org/10. 1016/j.nut.2020.110724

\section{Publisher's Note}

Springer Nature remains neutral with regard to jurisdictional claims in published maps and institutional affiliations.

Ready to submit your research? Choose BMC and benefit from:

- fast, convenient online submission

- thorough peer review by experienced researchers in your field

- rapid publication on acceptance

- support for research data, including large and complex data types

- gold Open Access which fosters wider collaboration and increased citations

- maximum visibility for your research: over $100 \mathrm{M}$ website views per year

At BMC, research is always in progress.

Learn more biomedcentral.com/submissions 